\title{
TRATAMENTO DAS IMAGENS NA FORMAÇÃO DO PEDAGOGO'
}

\section{Importância dos recursos técnico-visuais na escola requer formação que una o manejo dos códigos a uma pedagogia da imagem}

Ao fim dos anos 80 , dois filmes atravessaram o circuito de cinemas no Brasil causando grande impacto: falo de Blade Runner $^{2}$ e Sociedade dos poetas mortos ${ }^{3}$. Em que pesem as muitas leituras possíveis de cada obra, uma nos serve como ponto de partida ao transitar pelos dois filmes: o recurso à imagem técnica ${ }^{4}$, que remete o observador ao passado que, por sua vez, retorna ao presente, atualizando-o.

Em Blade Runner, os replicantes desejam tempo de vida e liberdade, por isso roubam fotografias de álbuns de família no intuito de, ao transferirem para si uma memória privada, presente nas imagens, adquirir uma identidade histórica, salvando-se de perseguições. As fotografias lhes servem de passaporte para um passado, autorizado pelo presente. Em Sociedade dos poetas mortos, por sua vez, o personagem Keating, novo professor da Academia Welton, inicia sua primeira aula utilizando-se das fotografias expostas na sala museu. Enquanto os alunos observavam suas semelhanças com os rostos juvenis inscritos nas imagens, Keating, en sussurro, dizia-lhes: "Aproveitem o dia rapazes... tornem suas vidas extraordinárias...". Suas palavras remetem a outras, ditas pelo também professor Lucien Febvre, quando advertia a seus alunos-historiadores: “(...) envolvam-se na vida intelectual, sem dúvida, em toda sua variedade. Sejam também juristas e sociólogos e psicólogos; não fechem os olhos ao grande movimento que, à sua frente, transforma, a uma velocidade vertiginosa, as ciências do universo físico"s.

Enquanto os pesquisadores que dialogavam com a historiografia seguiam Febvre, realizando estudos sobre a imagética em

\section{O AUTOR}

\section{Armando Martins de Barros}

Professor Assistente de História da Educação do Departamento de Fundamentos Pedagógicos, Universidade Federal Fluminense.

1. Educando o olhar: tratamento das imagens como fundamento na formação do pedagogo é o título do original deste trabalho apresentado no I Congresso Internacional de Comunicação e Educação realizado em maio, 1998, São Paulo. (N. Ed.)

2. EUA, 1982. Direção de Ridley Scott. Roteiro de Hampton Fancher e David Peoples, a partir do romance Do Androids Dream of Eletric Sheep?, de Phillip K. Dick. Fotografia de Jordan Cronenweth. Música: Vangelis.

3. EUA, 1987. Direção de Peter Weir. Roteiro de Peter Weir. Escrito originalmente por Tom Schulman. Produzido pela Touchstone Pictures.

4. Consideramos as imagens técnicas a partir da sistematização apresentada por Santaella: “(...) as imagens produzidas por conexão dinâmica e captação física de fragmentos do mundo visível, isto é, imagens que dependem de uma máquina de registro, implicando necessariamente a presença de objetos reais preexistentes; (...)". SANTAELLA, L. A imagem sob signo do novo. Imagens. Campinas: Unicamp, n. 3, dez. 1994. p. 35.

5. FEBVRE, L. Combates pela História. Lisboa: Presença, 1977. 
uma perspectiva multidisciplinar, as instituições educacionais, pouco afeitas a práticas seculares (laicas), mantinham-se estranhas ao envolvimento com os códigos não-verbais. Nessa perspectiva, o recurso à fotografia - nas palavras de Dubois, "matriz-mãe de todos os avanços técnicos, eletrônicos e informáticos" 6 -, remete-nos a dois campos importantes em nossas considerações: o papel da nova História Cultural na promoção do diálogo entre as práticas do olhar, historicizando a produção, circulação e significação das imagens, e as práticas escolares produzindo novos sentidos em fotografias para ou sobre a escola; e o papel desempenhado pelos cursos de Pedagogia na valorização das linguagens verbo-visuais quando da formação dos pedagogos.

\section{CONTRIBUIÇÃO DA HISTÓRIA CULTURAL: PRÁTICAS DO OLHAR}

Para muitos historiadores da imagem, dado o oculocentrismo ${ }^{7}$ subjacente à cultura Ocidental, os abalos sofridos em sua história se expressariam também como rupturas iconográficas. Em outras palavras, as instabilidades presentes nas Sociedades Ocidentais se expressariam por rupturas iconográficas em razão da saturação de imagens que circulam nos diversos segmentos sociais ${ }^{8}$.

Segundo Debray, inscreve-se em cada período histórico um inconsciente visual que determina os cânones da representação figurativa ${ }^{9}$. As representações sociais estariam introjetadas nos códigos imagéticos que predominariam por longas durações, em dominâncias sucessivas, implicando exclusões, sobreposições, imbricamentos, sucessões, em um revezamento de hegemonias cuja compreensão demandaria uma periodização com o concurso de múltiplos tempos ${ }^{10}$.

Nesse contexto, seria possível pensar o processo fotográfico - constituído na década de 30 do século XIX, por Talbot, na Inglaterra, Daguerre e Niepce, na França, e Hércules Florence, no Brasil - como imerso em uma longa história da imagem, envolvendo, inclusive, as práticas da pintura renascentista? Para os historiadores da imagem a resposta é afirmativa.

De fato, a percepção visual dominante na Baixa Idade Média foi redesenhada por um novo sistema gnosiológico (de conhecimento), determinado por sua vez pelas rupturas ocorridas nas relações econômicas, políticas e culturais ${ }^{11}$. Nesse quadro, a pintura medieval, até então caracterizada por um espaço descontínuo e fragmentado, foi superada na Renascença por um novo código figurativo que incorporava contribuições da Física, da Matemática, da Geometria. Fato que aproximou o visível do representado. Pintores como Leonardo da Vinci e Jean Baptiste Alberti finalmente sistematizaram os novos caminhos do ver com o concurso da perspectiva artificialis (perspectiva Clássica).

6. DUBOIS apud SAMAIN, E. Resenha: o ato fotográfico e outros ensaios. Revista Imagem. Campinas: Unicamp, n. 3, 1995. p. 107.

7. Oculocentrismo é uma expressão a que o autor recorre para expressar o centramento dos padrões imagéticos da Cultura Ocidental. (N. Ed.)

8. DEBRAY, R. Vida e morte da imagem. Rio de Janeiro: Paz e Terra, 1993. p. 91.

9. DEBRAY, R. Vida e... op. cit. p. 34. Para o autor, cada época teria seu teclado estético; uma sensoriedade coletiva, similar à mentalidade, "deteminada simultaneamente por uma escala de performances emotivas e por uma escala de prestígios sociais". Ibid, p. 285

10. DEBRAY, R. Vida e... op. cit.

11. MACHADO, A. A ilusão especular. São Paulo: Brasiliense, 1983. p. 70. 
Com o ordenamento do olhar, presente na perspectiva Renascentista, incorporou-se na pintura uma nova relação entre pintor e observador: o quadro tornou-se uma visão do agente enunciador, sujeitando o observador ao olhar do autor. Na fotografia, por sua vez, incorporando o mesmo padrão de representação, a imagem fundou-se em um olho único, imóvel: o observador vê pelos olhos do fotógrafo uma imagem que supõe "espelho do real", não desvelando a construção fotógrafo/câmara ${ }^{12}$.

Em uma leitura com ênfase nas disputas ideológicas, defende-se a tese da organicidade entre pintura Renascentista e processo fotográfico, por ambos exporem a estratégia operativa da burguesia que as inventou. Assim, a percepção da imagem fotográfica fundaria seu ilusionismo homológico na ideologia cristalizada na perspectiva central, expressão das lutas que teriam favorecido a burguesia mercantil nos séculos $\mathrm{XV}$ e $X V I^{13}$. Apesar da inegável contribuição dessa vertente na compreensão das relações entre imagens e sociedade, entendemos que permanecem lacunas na apreensão da rede de relações que envolve a atuação dos diferentes agentes que produzem, distribuem, censuram, ordenam, classificam e hierarquizam as imagens e suas significações.
Nesse sentido, a opção pelo estudo desses "silêncios" nos remetem inicialmente à contribuição de historiadores reunidos em torno da revista Annales: économies, so-

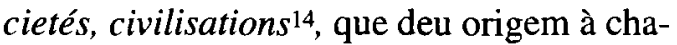
mada École des Annales. Rompendo com a tradição positivista, essa nova vertente historiográfica estimulou um primeiro desafio à hegemonia da fonte escrita, abrindo-se espaço para a iconografia, para o gestual, para os ritos, remetendo às estruturas mentais e às suas resistências na média e longa duração. Com a História das Mentalidades, reconhecemos a possibilidade em se lidar com os silêncios, alcançando-se, "por meio da confissão indireta, o que não foi formulado e nem sequer sentido claramente" 15 .

Em que pese a diversidade da produção e as diferentes vertentes que surgiram a partir da primeira geração de historiadores das Mentalidades, é indiscutível seu papel na incorporação ao campo historiográfico de temas como a família, os costumes, a criança, o livro, as linguagens, favorecendo a revolução documental vivida na década de 70. Tributária desse quadro, configurouse uma nova História Cultural, atenta ao não-formulado e às motivações inconscientes, sinalizando para as práticas e abrindo o diálogo com campos conexos como os da Literatura, Lingüística, Semiologia, Antropologia ${ }^{16}$.

12. MACHADO, A. A ilusão... op. cit. passim.

13. MACHADO, A. A ilusão... op. cit. p. 29. Observa o autor ser a percepção da perspectiva artificialis uma abstração, uma vez que o olhar está carregado de intenção e uma vez que o mundo visível não é dado como absoluto e total, mas sim como matéria que a percepção seleciona, amplia, ignora. op. cit. p. 66-75.

14. A revista dos Annales (Anais: economia, sociedade e civilização) foi fundada em 1929, na França, por Lucien Febvre e Marc Bloch. Em torno dessa publicação uniram-se outros intelectuais, com destaque para Fernand Braudel, dando origem a uma corrente inovadora que aborda a História de maneira mais ampla, ou seja, todos os fatos e objetos podem adquirir o status de fonte para o estudo da História. As categorias de cultura e cotidiano passam a ser fundamentais para essa nova abordagem. Para os fundadores da École des Annales (Nova História, História Cultural, História das Mentalidades), a História deve romper com a visão tradicional que tem como objeto de estudo a política do Estado, a visão oficial, a narrativa dos acontecimentos, tendo como fonte somente documentos oficiais. Ver mais sobre o tema: BURKE, P. (org.) A escrita da História. 2. ed. São Paulo: Novas Perspectivas/Unesp, 1992. (N. Ed.)

15. VOUVELLE, M. Ideologias e mentalidades. São Paulo: Brasiliense, 1991. p. 114.

16. VOUVELLE, M. Ideologia e... op. cit. p. 20. 
Preocupada com a produção e circulação dos dispositivos culturais, estudando seus suportes, historicizando seus agentes, resgatando seus significados no percurso dos diferentes usos por indivíduos e grupos, a História Cultural volta-se para as representações sociais que se expressam nas relações entre imagem e olhar. A nosso ver, nas posições de Roger Chartier encontram-se contribuições importantes na desnaturalização dessas práticas, constituídas no âmbito de disputas pela hegemonia de significados. Como observa Debray, “(...) Não há, de um lado, a imagem - material, única, inerte, estável - e, de outro, o olhar. Olhar não é receber, mas colocar em ordem o visível, organizar o seu sentido do olhar, assim como o escrito da leitura. (...) Na cidadela das imagens, uma história das utilizações e sociabilidades do olhar pode revisitar utilmente a História da Arte. (...) As culturas do olhar não são independentes das revoluções técnicas que, a cada época, vêm modificar o formato, os materiais, a quantidade de imagens de que uma sociedade deve assenhorear-se" 1 .

Para Chartier, as práticas discursivas seriam caracterizadas como produtoras de ordenamento e divisões, envolvendo formas diferenciadas de interpretação. Embora as práticas discursivas e sua apropriação se relacionem com as determinações sociais, uma análise apenas fundada nas tensões ideológicas, na identificação dos atores so- ciais, enfatizando apenas o enunciador como sujeito ativo, não daria conta da complexidade da questão: "Compreender estes enraizamentos exige, na verdade, que se tenham em conta as especificidades do espaço próprio das práticas culturais, que não é de forma nenhuma passível de ser sobreposto ao espaço das hierarquias e divisões sociais"18.

No âmbito da tradição historiográfica voltada para a educação, os estudos predominantemente enfatizam em sua análise $o$ discurso estatal, suas ações e ideologias, diluindo o foco sobre outros sujeitos que, na esfera civil, cotidianamente acatam, resistem ou reelaboram as ações governamentais. Na História Moderna, as práticas escolares - envolvendo as instituições, os professores, os alunos, os pais, os editores, os livros, as pedagogias, os conteúdos - interagem com as práticas do olhar, mediante o recurso a imagens em suportes como revistas pedagógicas, jornais para professores, livros didáticos ${ }^{19}$, álbuns de família ${ }^{20}$, cartões-postais ${ }^{21}$, filmes educativos ${ }^{22}$, programas em vídeo ou computador.

É urgente que os pedagogos se apropriem de conteúdos que lhes permitam a secularização das práticas escolares, no que diz respeito à educação do olhar. Como, então, pensar a especificidade desse campo envolvendo a historicização da produção da imagem, suas formas de apropriação, seus

17. DEBRAY, R. Vida e... op. cit. p. 91.

18. CHARTIER, R. A História Cultural - entre práticas e representações. Lisboa: Difel, 1990. p. 27-28.

19. Algumas incursões importantes vêm sendo realizadas em torno da obra de Comênius, com os primeiros livros didáticos ilustrados da era Moderna. Também as experiências de Paulo Freire, no âmbito da alfabetização, vêm sendo estudadas, ver MENDONÇA, A. M. Imagem e educação: um estudo da utilização de imagens no processo de alfabetização desenvolvido por Paulo Freire. Niterói: Faculdade de Educação, 1996. (Trabalho Monográfico.)

20. No primeiro semestre de 1997 foi iniciada pesquisa sobre as práticas privadas de registro fotográfico focalizando a escola. BARROS, A. M. de. O objeto da imagem e o sujeito do olhar: práticas escolares no álbum de família. Niterói: Projeto de Pesquisa SFP/PROPE/CNPq, 1997.

21. BARROS, A. M. de. Da pedagogia da imagem às práticas. A escola pública como cartão postal no Rio de Janeiro do início do século. Rio de Janeiro: Faculdade de Educação da Universidade Federal do Rio de Janeiro, 1997. (Tese de Doutorado.)

22. Os pioneiros trabalhos de Jônatas Serrano e Venâncio Filho na década de 20, anteriores e ao longo da gestão de Fernando de Azevedo na direção da Diretoria de Instrução Pública da cidade do Rio de Janeiro, ainda não tiveram o reconhecimento merecido como objetos da historiografia. 
esquemas de modelização, a formalidade de suas práticas - no âmbito da proposta curricular, quando as disciplinas existentes já concentram um conteúdo programático muitas vezes desproporcional à carga horária que lhes é oferecida? No caso específico do curso de Pedagogia da Universidade Federal Fluminense, uma experiência encontra-se em desenvolvimento: a atividade curricular Pedagogia da Imagem I: Fotografia.

\section{PEDAGOGIA DA IMAGEM NAS PRÁTICAS ESCOLARES}

No presente, políticas em diferentes instâncias públicas vêm sendo elaboradas e implementadas nos sistemas educacionais de Ensino Fundamental e Médio, tendo em vista a complementação da ação docente mediante o recurso intensivo a suportes verbo-visuais de natureza videográfica e infográfica. Mas a questão de fundo mantém-se intocada pois, nessas políticas, permanece a existência de objetivos não manifestos, voltados ao atendimento de grupos econômicos interessados na imagem-mercadoria e no mercado-educação ou, então, justificam o não investimento em outras necessidades prementes do sistema escolar.

Como o educador deve se posicionar frente às novas práticas do olhar que cruzam as práticas escolares, sem incorrer no viés da postura que apenas resvala na substituição da oralidade do professor pela verbo-visualidade técnica, mediada pela televisão ou pelo computador? Ao mesmo tempo em que denunciamos as estratégias de imposição de valores, conteúdos e olhares, envolvendo os novos recursos pedagógicos propostos pelo Estado e pelas empresas privadas, estamos, igualmente, atentos ao cotidiano que nossos alunos e seus pais realizam com e no encontro das imagens? Apreendemos, discutimos, implementamos em nossas metodologias as observações que realizamos com nossos alunos, em torno das significações e ressignificações produzidas nas esferas cotidianas do lazer televisivo, no contato infográfico inevitável nas casas bancárias ou supermercados? Ou mesmo no que diz respeito ao reordenamento visual e motor motivado pela cultura dos video games e pelas alterações das noções de tempo e espaço motivadas por nosso contato, em tempo real, com eventos planetários, via Internet ou TV a cabo?

Propor a incorporação na formação de pedagogos de conteúdos que discutam o campo e a pedagogia da imagem, implica não apenas a discussão (introdutória) das linguagens visuais, em sua significação e produção técnica - envolvendo necessariamente equipes multidisciplinares - como também, e principalmente, a historicização da cultura expressa nesses suportes e sua materialização no cotidiano através de uma rede silenciosa de práticas do olhar.

Incluir, na formação do pedagogo, conteúdos que tematizem as relações entre imagem e olhar impõe, em nosso entender, o amálgama histórico, ainda que seu estudo implique o concurso de domínios conexos que também se debruçam sobre a problemática da Antropologia da imagem, Sociologia da imagem, Semiologia etc. ${ }^{23}$

23. As reflexões no âmbito da Pedagogia vêm encontrando valiosos subsídios especialmente nos trabalhos de Sociologia de O1ga von Sinson, Tadeu Giglio e Mirian Moreira Leite; na historiografia, com Boris Kossoy, Maurício Lissovisky, Ana Maria Mauad, Antônio Oliveira Jr., Maria Inês Turazzo; na Antropologia, com Ligia Segalla e Etienne Samain; na Teoria da łmagem, com André Parente, Vani Kensky, Eduardo Morettin, dentre inúmeros estudiosos. MORETIN, E. Cinema educativo: uma abordagem histórica. Comunicação \& Educação São Paulo: CCA-ECA-USP/Moderna, n. 4, set./dez. 1995. p. 13-19. 
Nesse contexto, acreditamos na contribuição da História Cultural ao subsidiar a compreensão de práticas escolares que, numa longa duração, endossam imposições ou as reelaboram sobre o como, o porquê e o que ver.

Estamos atentos ao viés que tensiona a especificidade das atividades-fins para as quais se habilita o pedagogo, inserido na educação escolar ou em práticas a ela convergentes. Todavia, acreditamos que seja consensual o reconhecimento de que nossos administradores, supervisores, coordenadores, para melhor desenvolverem suas práticas, encontrem nos cursos de Pedagogia um espaço privilegiado de discussão sobre a educação dos sentidos e de apropriação de linguagens. Dessa forma, a proposta que a seguir abordamos busca responder à necessidade de situarmos o estatuto dos códigos não-verbais para aqueles que trabalham com o fenômeno pedagógico e que, em diversas instâncias, convivem, decidem e utilizam-se de mensagens visuais.

Para além do seu crescente tratamento na investigação histórico-educacional ${ }^{24}$, o recurso às imagens técnicas não é ainda objeto de reflexão sistemática nos cursos de Pedagogia, em que pese o trabalho que vem se desenvolvendo nos grupos de trabalho História da Educação e Educação e Comunicação, ambos vinculados à Associação Nacional de Pesquisa e Pós-Graduação em Educação - ANPEd. Nosso desafio, em projeto de longo prazo, é o de superarmos essa lacuna, construindo ações no que diz respeito ao ensino e à pesquisa que qualifiquem o pedagogo em formação para as crescentes demandas do ensino-aprendizagem das linguagens verbo-visuais.
Dirigida aos graduandos dos primeiros, segundos e terceiros períodos do curso de Pedagogia da Universidade Federal Fluminense, a atividade disciplinar Pedagogia da Imagem I: Fotografia, com sessenta horas-aula, apresenta como objetivos:

- subsidiar os estudos monográficos de graduação que tomem como temática a imagem técnica em sua produção/recepção, dirigida ao universo escolar;

- valorizar a preservação dos acervos imagéticos, especialmente fotográficos, filmográficos e videográficos que registrem aspectos da educação escolar;

- fomentar a interdisciplinaridade nos estudos da Pedagogia da Imagem, com ênfase na matriz epistemológica e no tratamento historiográfico de sua pedagogia;

- favorecer a discussão sobre metodologias que incorporem o tratamento das imagens enquanto códigos não-verbais no Ensino Médio e Fundamental;

- viabilizar a elaboração de exposições, ensaios fotográficos e vídeos voltados para o estudo das práticas do olhar envolvendo uma rede de agentes que produzem, partilham, reelaboram e disputam significados para as imagens.

Em uma avaliação ainda preliminar, além da desmistificação dos processos e equipamentos envolvidos na produção de imagens videográficas e fotográficas, os graduandos, ao interagirem intensivamente com os códigos não-verbais, revalorizam e atualizam as questões de forma e conteúdo, significante e significado, abordados a partir das habilitações em que irão atuar. Por outro lado, o curso vem favorecendo a cria-

24. No âmbito da historiografia educacional, após os pioneiros trabalhos de Zeila Demartini, vem crescendo o número de pesquisadores incursionando pelo campo. Podemos destacar Diana Vidal, Flávia Werle, Maria Ciavatta, Suely Oliveira, SteIa Borges, Luís Filipe Serpa. 
ção de uma cultura interdisciplinar, resultado da constituição de equipes multidisciplinares com a participação de professores e técnicos originados de diferentes departamentos e órgãos da universidade, atuando em torno dos conteúdos programáticos da disciplina ${ }^{25}$.

Resultado desses primeiros ensaios são produtos didáticos experimentais para o Ensino Médio e Fundamental, analisando as representações sobre a escola a partir do resgate do universo fotográfico familiar; as representações sobre o trabalho, analisando o percurso histórico das imagens do trabalho nas aquarelas de Debret, das imagens do trabalhador nas fotografias de Marc Ferrer e na produção-denúncia do Centro de Documentação Imagens da Terra ${ }^{26}$, construindo ensaios fotográficos sobre as relações entre o mundo do trabalho e o tempo do não-trabalho na vida dos homens trabalhadores.

\section{ESCOLA E ACESSO A LINGUAGENS TÉCNICO-VISUAIS}

Quantos de nós vêem? Para dizê-lo de modo ostensivo, todos, menos os cegos. Como estudar o que já conhecemos: a resposta a essa pergunta encontra-se numa definição de alfabetismo visual como algo além do simples enxergar, como algo além da simples criação de mensagens visuais. $O$ alfabetismo visual implica a compreensão e meios de ver e compartilhar o significado a um certo nível de universalidade ${ }^{27}$.

Em que pesem os riscos de subordinarmos o tratamento do não-verbal à lógica da escrita, ignorando a existência e especificidade dos códigos que significam as imagens técnicas em diferentes suportes, a questão apresentada por Dondis permanece não apenas atual como, igualmente, convoca a escola a reafirmar seu compromisso democrático com a socialização do patrimônio socialmente produzido, e que fundamentalmente é mediado pelas linguagens.

Embora ao longo da História as sociedades não tenham deixado de se organizar em torno de suportes visuais de adesão, o livre trânsito pelo território de produção e fruição das imagens sempre esteve restrito. A escola tem um papel na ampliação desse acesso e, hoje, os cursos de Pedagogia devem oferecer ao educador conteúdos que favoreçam o recurso crítico à imagética, historicizando suas práticas, seus discursos, seus agentes.

Acreditamos que o educador não deve prescindir dos recursos técnico-visuais contemporâneos, mas se impõe igualmente a contextualização da sociedade técnica que produz sua necessidade. A escola não pode ignorar um cotidiano onde os signos imagéticos são tomados como mercadoria $\mathrm{e}$, nesse posicionamento, deve assumir um papel mais efetivo e secular. Oferecer aos educadores os instrumentos básicos para a inteligibilidade da visualidade técnica é qualificar a escola para os desafios das novas formas de percepção e cognição que ora são gestadas.

A presença pedagógica da imagem educando os sentidos é histórica. Todavia, a escola permanece entre o fascínio, o receio e a paralisia. Mais do que práticas apenas voluntaristas em sua crítica ou recurso, urge

25. A experiência vem contando com o apoio do professor de fotografia Antônio Oliveira Jr., do Departamento de Comunicação Social, bem como dos técnicos em vídeo do Núcleo Audiovisual - NAV, da Universidade Federal Fluminense.

26. O Centro de Documentação Imagens da Terra, através da contribuição do fotógrafo João Ripper, vem participando de momentos da disciplina, apresentando a produção fotográfica da instituição e discutindo a metodologia de acompanhamento das comunidades que são fotografadas.

27. DONDIS, A. D. Sintaxe da linguagem visual. São Paulo: Martins Fontes, 1991. p. 227. 
discutirmos seu estatuto, seu campo, suas metodologias, de forma a permitir à escola intervir concretamente nas práticas sociais que autorizam ao olhar significar a imagem, identificando e dialogando com os atores sociais que teimam em ocultar-se.

Resumo: 0 artigo analisa o percurso da produçāo social da imagem, relacionando as práticas do olhar com a História da Cultura. Defende a necessidade da análise e compreensão da imagem a partir de sua contextualização sócio-histórica. Propõe a incorporação na formação de pedagogos de conteúdos que discutam o campo e a Pedagogia da imagem, tendo em vista o crescente papel da escola como mediadora na apropriação das linguagens verbo-visuais.

Palavras-chave: Pedagogia da imagem, escola, História Cultural, imagem, fotografia
Ao fim do século XX, quando a sociedade planetária constitui-se como videosfera e o homem é saturado de informações videoclipadas, como negar a urgência de refletirmos sobre os caminhos que a escola deve trilhar contra a imagem e com a imagem?

Abstract: The article analyses the trajectory of social production of images, relating viewing practices to the History of Culture. It defends the need for image analysis and comprehension from its social and historical contextualization. It proposes the incorporation, when educating teachers, of contents that discuss the field of image and pedagogy, keeping in mind the increasing role school has as a mediator in the appropriation of the verbal and visual languages.

Key words: Image pedagogy, school, Cultural History, image, photography 